\title{
Ueber den Speichel von Dolium galea.
}

Troschel hat in vorigen Herbste in Messina eine der grössten Schnecken, nëmlich Dolium galea Lam., zu untersuchen Gelegenheit gehabt. Quoy und Gaimard haben gefunden, dass die Gattungen Dolium und Cassis ungewöhnlich grosse Speicheldrüsen besitzen. Troschel hat diese Angaben, so wie auch weitere über die Form derselben bestätigt gefunden, und giebt neben einer Beschreibung des Baues dieses Thieres Folgendes hinsichtlich des Speichels selbst an, der von Bödecker analysirt worden ist.

Als man in einem Thiere die dünne Schale in der Gegend der Spira zerschlug, streckte das Thier sich selbst weit aus der Schale heraus und schob auch den Rüssel so weit aus dem Munde hervor, als es anging. Der Rüssel erlangte so eine Länge von 6 bis 7 Zoll, während er er eine Dicke von etwa 1 Zoll behielt. Mit diesem Rüssel fuhr das Thier nach allen Seiten umher, wie wenn es sich vertheidigen wollte. Als man den Rüssel nahe vor seinem abgestutzten, ein wenig trompetenartig erweiterten Enden mit zwei Fingern anfasste, um ihn näher in Augenschein zu nehmen, spritzte das Thier plötzlich einen dicken Strahl einer glashellen Flüssigkeit aus, der einige Fuss weit auf den Fussboden des Zimmers fiel. Auf den Kalkplatten, mit welchen das Zimmer ausgelegt war, sah man sogleich ein starkes schäumendes Aufbrausen.

Man behandelte nun ein zweites Exemplar ganz in solcher Weise, hielt aber ein Glas bereit, um die Flïssigkeit aufzufangen. Es war eine farblose, wasserhelle Flüssigkeit, ohne eine Spur von Schaum, welche stark sauer schmeckte, gleich die Zähne stumpf machte und in Berührung mit Kalk heftig brauste.

Es war kein Zweifel, dass diese Säure in den Speicheldrüsen gebildet war, durch die Untersuchung des Inhaltes derselben wurde diese Voraussetzung bestätigt. Bisher ist kein Beispiel bekannt, dass der Speichel eines Thieres eine so starke Lösung einer Säure enthält.

Als Troschel nun eine grössere Anzahl solcher Schnecken hatte einfangen lassen, zeigte es sich, dass sie nur wenig Flüssigkeit von sich gaben, und dann floss zugleich etwas Schleim mit aus, zumal wenn man durch einen Druck mit den Fingern auf den Ort, wo die Speicheldrüsen liegen, das Ausfliessen zu vermehren suchte. In den meisten Fällen hatten die Thiere schon vorher, etwa beim Einfangen, ihren Speichel wenigstens theilweise 
von sich gegeben, in einem Falle erhielt man jedoch von einem Thiere volle 6 Loth preuss. Gewichtes.

Es lässt sich voraussetzen, dass das Ausspritzen der Flüssigkeit durch die Contraction der musculösen Leibeswand des Thieres bewirkt wurde; durch einen Druck von Aussen auf die Gegend der Speicheldrüsen konnte man immer ein Ausspritzen bewirken, so lange noch Flüssigkeit in ihnen vorhanden war. Eigene Muskeln zum Comprimiren der hinteren Abtheilung der Speicheldrüsen scheinen nicht vorhanden zu sein.

Bödecker, der diesen Speichel im April d. J. von Troschel zur chemischen Untersuchung erhielt, giebt darüber Folgendes an:

Die fast ganz farblose, wasserhelle, nicht schleimige Flüssigkeit zeigte nicht die mindeste Spur von Zersetzung, Gährung, Schimmelbildung, Fäulniss oder dergl., obgleich sie $1 / 2 \mathrm{Jahr}$ in einem Stöpselglase aufbewahrt war. Sie besass keinen besonderen Geruch, aber stark sauren Geschmack und stark saure Reaction, ihr spec. Gewicht war 1,039. Beim Kochen blieb sie völlig klar, auch wenn zuvor die grosse Menge der freien Säure fast ganz durch Natron gesättigt war; sie enthielt also kein Albumin. Beim Erwärmen mit überschüssigem Natron liessen sich geringe Mengen von Ammoniak erkennen. Baryt- und Silberlösung zeigten die reichliche Anwesenheit von Schwefelsäure und Salzsäure. Die nach dem Verdampfen und Einmischen zurïckbleibenden unorganischen Stoffe erwiosen sich als Sulphate von Talkerde, Kali und Natron, mit wenig Kalk. Der Gehalt an organischen Stoffen war so gering, dass selbst zur qualitativen Ermittelung derselben das Material nicht genügte; die neutralisirte Flüssigkeit gab weder Reactionen auf Harnstoff, noch auf Zucker. Bei der Destillation wurde mit dem Wasser nur Salzsäure und sehr wenig Schwefelsäure verflüchtigt.

Nach der quantitativen Analyse, welche Bödecker noch unternahm, enthält demnach dieses Schneckensecret in 100 Theilen:

0,4 freie wasserfreie Salzsäure $(\mathrm{HCl})$

2,7 freies Schwefelsäurehydrat $\left(\mathrm{HO}, \mathrm{SO}^{3}\right)=2,2$ Proc. wasserfreier Schwefelsäure

1,4 wasserfreie, mit Basen zu neutralem Salze verbundene Schwefelsäure

1,6 Talkerde, Kali, Natron, etwas Ammoniak, sehr wenig Kalk, nebst organischer Substanz

9,39 Wasser

100,0 . 
Eine so zusammengesetzte Flüssigkeit nimmt in mehrfacher Weise unser Interesse lebhaft in Anspruch: dem Zoologen und Physiologen stellt sich die Frage entgegen: Als was für ein Secret oder Excret ist diese Flüssigkeit nach dem Ergebnisse der anatomischen Untersuchung zu betrachten? Welche Functionen kommen der Flüssigkeit zu, wenn sie nicht als ein einfaches Excret zu betrachten ist?

Das Thier spritzt den Speichel mit einer ziemlich grossen Kraft aus dem Munde hervor. Dass dieser merkwürdige Speichel nicht ausschliesslich und nach seiner ganzen Menge zur Verdauung verwendet wird, liegt sehr nahe. Dagegen ist es sehr wahrscheinlich, dass er ein Vertheidigungsmittel des Thieres bilde. Die Schalen der Gattung Dolium besitzen eine grosse Apertur und das Thier hat keinen Deckel, um diese zu verschliessen. Es ist daher allen Angriffen frei ausgesetzt, und wird sich der Süure mit Erfolg gegen seine Feinde bedienen können. Es darf dabei aber nicht übersehen werden, dass die Flüssigkeit immer nur unter Wasser zur Anwendung kommen, also hier nicht auf weite Entfernung wirken kann.

Da die Gattung Cassis zufolge der Angaben von Quoy und Gaimard mit ganz ähnlichen Speicheldriisen versehen ist, so ist wohl die Voraussetzung zu machen, dass diese Thiere eine ähnliche Zusammensetzung des Speichels haben. Sie besitzen zwar einen Deckel, derselbe ist aber nicht gross genug, um die ganze Apertur zu schliessen.

Die Verwendung des Speichels als Vertheidigungsmittel wuirde einen theilweisen Einfluss auf die Nahrungsstoffe, als die Verdauung fördernd, an sich nicht ausschliessen. Man könnte sich denken, dass die Nahrungsmittel vor der Einnahme durch den Speichel gleichsam präparirt würden, oder dass sie während oder nach der Einnahme durch ihn verdaulicher gemacht würden. Eine Beobachtung sprichtjedoch nicht direct gegen eine solche Function des Speichels. Diese Schnecken sind nämlich phytophag, sie fressen Seetang, mit dem der Meeresgrund bedeckt ist. Während zuweilen der Schlund und Magen ganz leer gefunden wurden, so ist in andern Fällen der Magen ganz mit grossen Fetzen der verschiedensten Tangarten erfüllt; ja Streifen von 4 Zoll Länge und dariiber lagen im Schlunde, während andere mehr blattartige Stïcke zusammengedrückt und, wie es schien, noch unverändert neben ihnen Platz 
hatten. Als Troschel vor Kurzem, nachdem die Exemplare viele Monate in Weingeist gelegen hatten, versuchen wollte, ob etwa der saure Speichel auf diesen Tang einen Einfluss ausübe, bemerkte er, dass an manchen aus dem Magen der Schnecke genommenen Tangstücken noch deutliche Kalkreste von Thieren, kleinen Polypen oder dergl. hafteten. In den sauren Speichel gelegt, brausten diese Kalktheilchen sogleich heftig und waren bei ihrer Winzigkeit in kurzer Zeit zerstört, so dass unter der Loupe der Vorgang begann und in einer Minute endete. Aus dieser Beobachtung lässt sich nun mit Sicherheit der Schluss ziehen, dass der Tang weder vor noch während des Fressens mit dem sauren Speichel in Berührung gekommen war; denn sonst müssten unfehlbar die geringen Kalktheilchen schon früher zerstört worden sein. Aus der Lage der Speichelöffnungen vor der Zunge am vorderen Rande des Rüssels darf man ferner wohl schliessen, dass nach der Vollendung des Fressactes kein Speichel mehr in den Magen entleert wurde. So kommt man zu dem Resultate, dass dieser saure Speichel als die Verdauung fördernd nicht angesehen werden darf.

Sehr viel schwieriger erscheint die Beantwortung der Frage, wie das Thier diese Flüssigkeit zu bereiten im Stande ist, und wie es dieselbe in seinem Innern zu bewahren vermag, ohne selbst dadurch Schaden zu leiden. Die Häute, mit denen der Speichel im Innern in Berührung kommt, müssen natürlich der Art sein, dass sie nicht durch ihn angegriffen werden. Auch die Schale des Thieres ist gegen die Einwirkungen der Säure, namentlich auf der innern Oberfläche, geschützt, dieselbe ist von einem dünnen, glatten Ueberzuge bedeckt, den die Säure nicht angreift; nur an verletzten Stellen bemerkt man sogleich durch Entwickelung von Luftbläschen, dass die Säure in Wirkung tritt.

Eine weitergreifende Wichtigkeit möchte die Entdeckung dieses Speichels von Dolium galea dadurch erlangen, dass das Vorkommen desselben vielleicht nicht so vereinzelt unter den Schnecken sein dürfte. Es lässt sich vermuthen, dass andere Schnecken, wenn auch nur in geringerer Menge, sauren Speichel bereiten können, dessen Entdeckung durch das jetzt bekannte Beispiel erleichtert sein wird. Sollten etwa diejenigen Schnecken, ron welchen es bekannt ist, dass sie Lö̈cher durch die Muschelschalen bohren, um sich der Einwohner zu bemächtigen, einen ähnlichen Speichel besitzen? Wenngleich sich hier 
die Vermuthung aufdrängt, dass die bohrenden Muscheln, über deren Bohrthätigkeit, trotz der grossen darauf verwendeten Aufmerksamkeit, man noch immer nicht zu einer endgültigen Entscheidung gekommen ist, etwa in ihrem Speichel eine kräftige, chemische Unterstützung finden möchten, so wird diese Vermuthung sogleich dadurch abgewiesen, dass man den Muscheln bisher im Allgemeinen die Speicheldrüsen abgesprochen hat. (Ber.der Akad.der Wissensch. zu Berlin. 1854.)

$B$.

\section{Ueber den blauen Farbstoff aus dem Harne.}

Dr. A. Martin hat auf L. A. Buchner's Veranlassung in dessen Laboratorium die umfassendsten Versuche zur Ergründung der Entstehung des blauen Farbstoffs im Harne angestellt und hierüber unter dem Titel: "Ueber das Urokyauin und einige andere Farbstoffe im Menschenharn. München 1845." eine Inaugural-Abhandlung veröffentlicht. $B$ u ch ner theilt hier Einiges über den durch Salzsäure erzeugten blauen Harnstoff mit, den Martin statt Cyanurin, welche Bezeichnung von Braconnot vorgeschlagen worden ist, passender Urokyanin genannt hat.

Zur Darstellung des Urokyanins wurde das durch Salzsäure aus dem bläulich gewordenen Harn verschiederer kranker Individuen nach lïngerem Stehen Ausgeschiedene auf einem Filter gesammelt, mit Wasser ausgewaschen, getrocknet und dann sammt dem zerschnittenen Filtrum so lange mit Alkohol ausgekocht, als dieser noch merklich blau gefärbt wurde. Das nach dem Verdampfen der heiss filtrirten alkoholischen Flüssigkeit $\mathrm{Zu}$ rückgebliebene wurde dann zuerst mit kaltem Aether, der sich schön amaranthroth färbte, und hierauf mit kaltem Alkohol, der dadurch eine schöne burgunderrothe Färbung bekam, ausgezogen; das so von einem oder ein Paar, mit dem Urokyanin gewöhnlich auftretenden rothen Farbstoffen befreite Pulver endlich behandelte man mit kochendem Alkohol, in welchem sich das Urokyanin selbst auflöste und woraus sich dieser Farbstoff nach einiger Zeit grösstentheils wieder präcipitirte.

Das auf solche Weise dargestellte Urokyanin besass folgende Eigenschaften: Es stellte ein blauschwarzes feines Pulver ohne alles krystallinisches Gefüge dar, welches zwischen Papierfl̈̈chen gerieben, dieselben schön 